\title{
Bidirectional Links and Concurrent Development of Parent-Child Relationships and Boys' Offending Behavior
}

\author{
Loes Keijsers \\ Utrecht University
}

\author{
Rolf Loeber \\ University of Pittsburgh
}

\author{
Susan Branje and Wim Meeus \\ Utrecht University
}

\begin{abstract}
This study examined different types of longitudinal associations (i.e., directional links and overlapping developmental changes) between children's delinquency and the quality of parent-child relationships from middle childhood to late adolescence. We used 10-wave interview data of 503 boys, their primary caregivers, and their teachers. Our first aim was to unravel the direction of effects between parent-child relationships and children's offending. Cross-lagged panel models revealed bidirectional links over time between poorer quality parent-child relationships and boys' offending across late childhood (age 7-10), early adolescence (age 10-13) and middle adolescence (age 13-16). Second, we examined the associations between mean changes in delinquency, on the one hand, and mean changes in relationship quality, on the other hand. Although parent-child relationships improved during childhood, their quality decreased in early adolescence and remained stable in middle adolescence. Delinquency increased only in middle adolescence. In five out of six models, the slope factors of relationship quality and offending were strongly correlated, indicating that stronger increases in delinquency were associated with stronger decreases in parent-child relationship quality across childhood, early adolescence, and middle adolescence. The discussion focuses on the theoretical implications of these two types of longitudinal associations.
\end{abstract}

Keywords: delinquency, parent-child relationship, longitudinal, development, cross-lagged panel model, growth curve modeling, reciprocal

A vast number of youths engage in delinquent acts from childhood into adolescence. Many scholars have theorized that a poor parent-child relationship is a risk factor for the development of delinquency both in childhood and adolescence (e.g., Glueck \& Glueck, 1950; Gottfredson \& Hirschi, 1990; Loeber \& Dishion, 1983; Patterson \& Stouthamer-Loeber, 1984; Sampson \& Laub, 1993). For instance, social control theory (Hirschi, 1969) posits that delinquents are relatively free from the commitments to school, and intimate attachments to peers and parents, that bind most people to a life within the law. When tempted to commit a delinquent act, thinking about parents' responses may inhibit children from actually becoming delinquent. The quality of parent-

This article was published Online First August 15, 2011

Loes Keijsers, Susan Branje, and Wim Meeus, Research Center Adolescent Development, Utrecht University; Rolf Loeber, Department of Psychiatry, University of Pittsburgh.

This study was supported by a grant from the Netherlands Organisation for Scientific Research (NWO, 400-04-183), by grant 2005-JK-FX-0001 from the Office of Juvenile Justice and Delinquency Prevention (OJJDP), grants MH 50778 and 73941 from the National Institute of Mental Health, grant No. 11018 from the National Institute on Drug Abuse, a grant from the Department of Health of the Commonwealth of Pennsylvania, and a grant from the Centers for Disease Control (administered through OJJDP).

Correspondence concerning this article should be addressed to Loes Keijsers, Research Center Adolescent Development, Utrecht University, P.O. Box 80.140, Utrecht, Netherlands, 3508TC. E-mail: 1.keijsers@uu.nl child relationships thus plays a major role in children's delinquency. Parent-child relationship quality may also affect delinquency more indirectly, however. Specific parenting practices such as parental monitoring and control may fail to have the desired positive effect on children's wellbeing in lower-quality relationships, due to children's lower receptivity to socialization initiatives (Baumrind, 1991; Darling \& Steinberg, 1993) and children's lack of willingness to disclose relevant information to parents (Keijsers, Branje, Frijns, Finkenauer, \& Meeus, 2010; Kerr, Stattin, \& Trost, 1999). There is, moreover, ample empirical evidence that delinquent children and adolescents have poorer relationships with parents (e.g., Dishion \& McMahon, 1998; Hoeve et al., 2009; Keijsers, Frijns, Branje, \& Meeus, 2009; Laird, Pettit, Bates, \& Dodge, 2003; Loeber \& Stouthamer-Loeber, 1986; Meeus, Branje, \& Overbeek, 2004; Patterson \& StouthamerLoeber, 1984).

Nevertheless, the socialization of children into well-behaved individuals may not be adequately understood as a solely unidirectional phenomenon, with parents affecting their children. Instead, socialization may be best understood as a reciprocal, interactive process. Under such a conceptualization, both parents and children are active agents and children's misbehavior has the potential to evoke inadequate parenting (Bell, 1968; Kuczynski \& Parkin, 2007; Maccoby, 2007). With respect to the development of delinquency, perhaps the most influential work in this vein is Patterson's coercive family theory. This viewpoint proposes that 
young children's disobedience and misbehavior may initiate feedback loops, consisting of reciprocal negative influences of parents and children upon one another, resulting in deteriorating parentchild relationships and increasing child misbehaviors and delinquency (e.g., Granic \& Patterson, 2006; Patterson, Bank, \& Stoolmiller, 1990). The longitudinal relation between poor parent-child relationships and delinquency from middle childhood to adolescence may thus be understood in terms of a reciprocal process, in which poorer parent-child relationships precede higher levels of delinquency, and in which engagement in delinquency evokes parenting of poorer quality, in turn (review: Lytton, 1990). In the longer run, these reciprocal relative influences may lead to overlapping, mean-level developmental changes in relationship quality and offending. For example, the increase of a child's delinquency during adolescence may be steeper when the deterioration of his parent-child relationship during adolescence is more pronounced.

Because it is still unclear as to how the linkages between parent-child relationships and offending unfold during children's development, two types of longitudinal associations will be studied in the present paper. This study takes a bidirectional perspective on parent-child socialization, and thus the first aim is to test whether parent-child relationships affect subsequent offending, whether offending affects subsequent parent-child relationships, or whether both influences occur, simultaneously in a bidirectional fashion. The second aim is to examine the overlapping developmental changes in parent-child relationships and changes in delinquency. That is, we will test whether the rate of mean-level changes in parent-child relationships are linked to the rate of mean-level changes in children's delinquency.

\section{Bidirectional Longitudinal Effects Between Parent-Child Relationships and Delinquency}

Empirical studies from an interactional and bidirectional perspective have generally supported the idea that parent-child relationships and child problem behaviors affect each other in a reciprocal nature (e.g., Arim, Dahinten, Marshall, \& Shapka, 2011; Branje, Hale, \& Meeus, 2008; Keijsers, Branje, Van der Valk, \& Meeus, 2010; Patterson et al., 1990; Stewart, Simons, Conger, \& Scaramella, 2002; Stice \& Barrera, 1995; Willoughby \& Hamza, 2010). Such effects have been demonstrated both in middle childhood and in adolescence (Pardini, Fite, \& Burke, 2008). That is, not only may poor parent-child relationships precede children's engagement in delinquency, but children's delinquent behavior may also negatively affect the quality of the parent-child relationship over time.

Distinct changes occur in children's lives and the relationships with their parents from middle childhood to adolescence, however, and the reciprocal associations between parent-child relationships and offending may therefore vary by age. As children enter high school, hanging around with friends and peers becomes a more preferable way of spending leisure time than being at home with their parents (Berndt, 1982; Brown, 2004). As a result, an increasing number of hours of adolescents' daily lives are consumed by activities that go unsupervised by parents (Csikszentmihalyi, Rathunde, \& Whalen, 1993; Keijsers et al., 2009; Larson, Richards, Moneta, Holmbeck, \& Duckett, 1996; Patterson \& StouthamerLoeber, 1984). In addition, parental authority and the legitimacy of parental involvement and decision making decrease during the adolescent years (Smetana, 1988), with teenagers desiring and claiming an increasing say in their personal lives, behaviors, and activities (Bosma et al., 1996; Smetana \& Asquith, 1994). Given these expansions of children's social worlds, and the declining authority of parents in adolescence, it might be that parent-child relationships affect children's problem behaviors more profoundly during childhood than during adolescence (Loeber, Slot, \& Stouthamer-Loeber, 2008; Patterson, DeBaryshe, \& Ramsey, 1989; Reid \& Patterson, 1989). Monitoring of adolescents' whereabouts and friendships becomes increasingly important for preventing problem behaviors (Reid \& Patterson, 1989), however, and monitoring may only be effective in families with high levels of involvement, low levels of coercion, and high levels of support (Dishion \& McMahon, 1998; Keijsers, Branje, Van der Valk et al., 2010; Keijsers et al., 2009; Kerr et al., 1999) — hence, in higherquality relationships. As such, it could also be that parent-child relationships and delinquency remain bidirectionally linked during adolescence.

Empirical studies do not give consistent results with regard to the age-dependent reciprocal association between parent-child relationships and offending. Some studies seem to confirm the idea that associations between parenting and offending are stronger in childhood than in adolescence (meta-analysis: Hoeve et al., 2009). Others, however, have stressed that the quality of parent-child interactions remains predictive of offending in adolescent years, and that monitoring-related qualities of the parent-child relationship and parental involvement, in particular, may be more strongly related to problem behaviors in adolescence than in childhood (Fite, Colder, Lochman, \& Wells, 2006; Frick, Christian, \& Wootton, 1999; Keijsers, Branje, Van der Valk et al., 2010; Kerr \& Stattin, 2000; Laird et al., 2003; Pardini et al., 2008). There is a relative paucity of studies comparing the strength of reciprocal longitudinal effects between the quality of parent-child relationships and delinquency in different age periods. The first aim of the current study is to examine whether reciprocal linkages between the quality of parent-child relationships and children's offending are present in, and differ between, the periods of middle childhood, early adolescence, and middle adolescence.

\section{Developmental Linkages Between Parent-Child Relationships and Delinquency}

Although the aforementioned studies examining these relative longitudinal effects have enhanced our understanding of potentially mutual associations between poorer parent-child relationships and delinquency, they do not reveal anything about the absolute level of offending or relationship quality over time (Conger, Lorenz, \& Wickrama, 2004). Coercive family process theory (Granic \& Patterson, 2006) also explicitly describes the cooccurring, mean-level developmental changes in family relationships and offending that may result from negative reciprocal influences between children and their parents. Studying these overlapping developmental processes can provide valuable information about the downward spiral that can occur when the level of delinquency increases and the quality of parent-child relationships decreases (Granic \& Patterson, 2006).

Previous studies have shown that mean-level developmental changes occur both in parent-child relationships and in delinquency. Empirical findings have demonstrated a normally occur- 
ring pattern of changes in parent-child relationships: Parent-child communication decreases during the adolescent years and parents become less knowledgeable on their child's leisure time activities over time (Keijsers, Branje, Frijns et al., 2010; Keijsers et al., 2009; Laird et al., 2003; Loeber et al., 2000; Masche, 2010; Smetana, Crean, \& Daddis, 2002). It is therefore not surprising that the quality of the parent-child relationship (temporarily) decreases in middle and late adolescence (De Goede, Branje, \& Meeus, 2009; Loeber et al., 2000). In addition to these changing family dynamics, many youths engage in delinquent acts during their adolescent years (Moffitt, 1993). Delinquent acts peak sharply around age 16, and drop precipitously in young adulthood (i.e., an age-crime curve takes place; e.g., Farrington, 1986; Loeber, Farrington, Stouthamer-Loeber, \& Raskin White, 2008; Sampson \& Laub, 1993; Tremblay \& Nagin, 2005).

Much less is known about the association between these meanlevel developmental changes in parent-child relationships and the development of juvenile delinquency (Granic \& Patterson, 2006). The majority of empirical studies examining such associations have focused on the development of delinquency, and have predicted it from parent-child relationships measured at one occasion (e.g., Deković, Buist, \& Reitz, 2004; Duncan, Duncan, \& Strycker, 2000; Galambos, Barker, \& Almeida, 2003; Jang, 1999). Such a strategy holds the implicit assumption that parent-child relationships are stable. Studies linking mean-level development of delinquency to mean-level development of parenting are more scarce. Two studies on adolescents have shown that a stronger decline of parental knowledge (Laird et al., 2003) and a stronger decline of adolescent disclosure (Keijsers et al., 2009) are related to stronger increases in adolescent delinquency. We are not aware, however, of studies testing these correlated mean-level developmental changes between offending and the quality of the parent-child relationship, nor of studies testing this across the span of childhood and adolescence. The second aim of the current study is therefore to address these issues.

\section{The Present Study}

Taken together, the aims of the current study are twofold. First, we take an interactional and bidirectional perspective to examine the longitudinal directionality of effects between offending and parent-child relationships. We expect to find T1 associations between poorer parent-child relationships and delinquency. We also predict bidirectional longitudinal effects, with relatively poorer parenting preceding relatively higher levels of delinquency, and relatively higher levels of delinquency preceding poorer parenting. Second, we examine whether there is an overlap between the mean-level development of offending and the mean-level development of parent-child relationship quality. We hypothesize significant associations between stronger changes toward higher levels of delinquency and stronger changes toward poorer parentchild relationship quality. For both research aims, we will study differences between middle childhood, early adolescence and middle adolescence. Moreover, because parents and adolescent children may live in the same environment but in separate realities (Csikszentmihalyi \& Larson, 1984), the present study uses reports on parent-child relationships from the perspective of both boys and parents.

\section{Method}

\section{Sample}

This study uses data from the Pittsburgh Youth Study, a large ongoing longitudinal study on inner-city boys. Three cohorts of boys in Grade 1, 4, and 7 were screened on antisocial behavior. Based on a composite score of parental, teacher, and participant information, $30 \%$ most antisocial boys were identified as high-risk and the remainder as lower risk (see for a detailed description of this procedure: Loeber, Farrington, Stouthamer-Loeber, \& Van Kammen, 1998).

The current study is based on data of the youngest cohort ( $n=$ 503; 256 high risk and 247 lower risk). At the first follow-up, four months after the screening, the average age of participants was 6.9 years. Just over half of this sample was African American (57.8\%), and the remainder was Caucasian. The primary caretaker, the persons who claimed to have main responsibility for the boy, was almost exclusively female $(96.8 \%$; of which $92.2 \%$ was the biological mother). ${ }^{1}$ Demographics of this sample were representative for the school sample it was drawn from (Loeber et al., 1998).

\section{Procedure}

Data collection took place by interviewing the primary caretaker, boy, and teacher. The first eight follow-ups were done at 6-month intervals, and the subsequent six assessments were done with an annual time interval. For the purpose of consistency of presentation, half-year waves were merged into yearly scores in the present study, leading to 10 annual waves of delinquency and parent-child relationship quality (age 7 to 16). The cooperation rate throughout the study was high (average $82.3 \%$; and $83.2 \%$ on the final assessment; Loeber et al., 2002).

\section{Measures}

The General Delinquency Seriousness Classification (Loeber et al., 1998), based on combined reports of parents (CBCL, Lifetime scale), teacher (TRF), and the child itself (SRA or SRD) was used to classify delinquent behaviors into four levels: Level 0 represented absence of delinquency; Level 1 consisted of minor delinquency at home, such as minor vandalism and stealing at home, or minor delinquency outside home, such as minor vandalism and fire setting with insignificant damage, or shoplifting; Level 2 was comprised of moderately serious delinquent acts, including pick pocketing, stealing from a car, using illegal checks, and carrying weapons; Level 3 represented serious delinquency, including murder, rape, robbery, and selling hard drugs; and two or more serious level 3-offenses were assessed as level 4. Boys were classified as belonging to the category matching the most serious delinquent act they had committed in the last year, and 6-month waves were combined by placing a youth at the highest level attained across the two waves (for a more detailed description, see Loeber, Farrington et al., 2008). Previous studies have shown adequate psychometric properties and predictive validity of this measure (Farrington, Loeber, Stouthamer-Loeber, Van Kammen, \& Schmidt,

\footnotetext{
${ }^{1}$ When fathers were the primary caretaker, boys' reports on fathers were included in the scale-score.
} 
1996; Loeber, Farrington et al., 2008). One-year stabilities ranged between .36 and .54 (see also Appendix 1).

Parent-child relationship quality. Using the relationship with primary caretaker questionnaire (Stouthamer-Loeber, Loeber, Wei, Farrington, \& Wikstrom, 2002), the affective quality of the parent-child relationship was assessed in terms of negative and positive aspects of the relation. Boys filled in 13 items (e.g., "How often have you liked being your mother's/ father's child?") and parents 16 items (e.g., "How often have you enjoyed spending time with your son?"). Answers were rated on a 3-point Likert scale: $1=$ Almost never, $2=$ Sometimes, and $3=0$ ften, and were recoded so that higher levels represent poorer relationship quality. Internal consistency of this scale was high in the current study (ranging between $\alpha=.83$ and $\alpha=.90$ for parental reports and between $\alpha=.73$ and $\alpha=.87$ for children's reports). Previous studies have shown that this scale has adequate construct and convergent validity in the prediction of delinquency (e.g., Hoeve et al., 2008; Stouthamer-Loeber et al., 2002). One-year stabilities ranged between .46 and .82 (see also Appendix 1). Correlations between reports of children and parents ranged between .12 and $.34(p<.05)$.

\section{Analyses}

Our first aim was to test the (bi)directional associations over time between poor parent-child relationships and offending. To this end, we tested cross-lagged panel models, including relative stability, correlated changes, and cross-lagged effects (Kline, 2005). To test for age differences, we constrained the correlated changes and cross-lagged effects to be equal across time intervals (i.e., 7-10, 10-13, and 13-16 years) and compared the fit of such a constrained model with an unconstrained one. Our second research aim was to test associations between mean-level changes in parent-child relationship quality and mean-level changes in delinquency. For this purpose, we used univariate latent growth curve modeling to examine the mean-level changes in offending and the mean-level changes in parent-child relationship quality, per age interval (i.e., 7-10, 10-13, and 13-16 years). We then used multivariate latent growth curve modeling (Duncan, Duncan, Strycker, Li, \& Alpert, 1999) to examine whether these developmental changes were linked to each other. In these models, links between relationships and offending are evaluated at the level of the growth trajectories, as a whole, and not at the level of the repeated measures from one time point to the next, as is done in crosslagged panel models. Age differences were tested by examining the overlap in confidence intervals of the correlation between changes in delinquency and relationship quality. In all models, missing data were included in model estimations using an EM algorithm (Allison, 2003). All models were analyzed separately for parent-reports and boys' reports of relationship quality.

\section{Results}

\section{Reciprocal Effects}

Descriptive statistics and correlations, on which the structural equation models are based, are presented in Table 1. The full correlation matrix can be found in Appendix 1. To test whether bidirectional linkages existed between poor parent-child relationships and offending, we examined a cross-lagged panel models. We first tested whether the cross-lagged effects and/or correlated change varied between childhood, early adolescence and middle adolescence, but did not find such age effects. That is, freely estimating the cross-lagged effects per age group did not improve the fit of a model in which the cross-lagged effects were constrained to be invariant across age groups: child-reported: $\Delta \chi^{2}=$ 5.69, $d f=4, p=.16$; parent-reported: $\Delta \chi^{2}=4.73, d f=4, p=$ .36. The same was found for correlated changes: child-reported: $\Delta \chi^{2}=2.56, d f=2, p=.28$; parent-reported: $\Delta \chi^{2}=3.98, d f=$ $2, p=.14$. Two models ranging from age 7 to 16 , with correlated changes and cross-lagged effects constrained across time, were thus reported. As presented in Table 2, these models had good model fit statistics.

In line with our expectations, there were significant $\mathrm{T} 1$ associations between poorer parent-child relationship quality and higher levels of offending in these models $\left(r_{\text {child }}=.23, p<.001\right.$; $\left.r_{\text {parent }}=.31, p<.001\right)$. These associations were also found at each subsequent measurement wave (i.e., correlated changes ranged between .05 and $.14, p<.001)$.

Table 1

Descriptive Statistics and Correlations

\begin{tabular}{|c|c|c|c|c|c|c|c|c|c|}
\hline \multirow[b]{2}{*}{ Measurement } & \multicolumn{2}{|c|}{$\begin{array}{l}\text { 1. Offending (multi- } \\
\text { informant) }\end{array}$} & \multicolumn{2}{|c|}{$\begin{array}{l}\text { 2. Bad relationship } \\
\text { quality (parent) }\end{array}$} & \multicolumn{2}{|c|}{$\begin{array}{l}\text { 3. Bad relationship } \\
\text { quality (child) }\end{array}$} & \multicolumn{3}{|c|}{ Correlations } \\
\hline & Mean & $S D$ & Mean & $S D$ & Mean & $S D$ & 1.-2. & 1.-3. & 2.-3. \\
\hline Age 7 & 0.62 & 0.69 & 22.52 & 4.39 & 18.33 & 3.53 & $.31^{* * *}$ & $.23^{* *}$ & $.12^{* * *}$ \\
\hline Age 8 & 0.57 & 0.67 & 22.45 & 4.68 & 17.79 & 3.46 & $.26^{* *}$ & $.24^{* *}$ & $.18^{* * *}$ \\
\hline Age 9 & 0.55 & 0.67 & 22.38 & 4.82 & 17.58 & 3.57 & $.37^{* * *}$ & $.22^{* *}$ & $.17^{* * *}$ \\
\hline Age 10 & 0.68 & 0.87 & 22.14 & 4.98 & 17.45 & 3.57 & $.33^{* *}$ & $.21^{* * *}$ & $.14^{* * *}$ \\
\hline Age 11 & 0.71 & 0.92 & 22.50 & 5.42 & 17.74 & 4.23 & $.29^{* * *}$ & $.27^{* * *}$ & $.19^{* * *}$ \\
\hline Age 12 & 0.74 & 0.96 & 22.55 & 5.50 & 18.50 & 4.24 & $.23^{* *}$ & $.29^{* * *}$ & $.17^{* * *}$ \\
\hline Age 13 & 0.84 & 1.03 & 22.75 & 5.88 & 19.05 & 4.37 & $.31^{* * *}$ & $.26^{* *}$ & $.20^{* * *}$ \\
\hline Age 14 & 0.83 & 1.08 & 22.26 & 5.64 & 19.22 & 4.31 & $.33^{* *}$ & $.26^{* *}$ & $.20^{* * *}$ \\
\hline Age 15 & 0.83 & 1.07 & 22.35 & 5.69 & 19.41 & 4.54 & $.27^{* * *}$ & $.34^{* * *}$ & $.28^{* * *}$ \\
\hline Age 16 & 0.75 & 1.10 & 22.27 & 5.75 & 19.07 & 4.32 & $.34^{* *}$ & $.23^{* *}$ & $.34^{* * *}$ \\
\hline
\end{tabular}

Note. The informant is indicated between parentheses.

${ }^{*} p \leq .05$. ** $p \leq .01$. 
Table 2

Standardized Parameter Estimates of Cross-Lagged Panel Models Including Bad Relationship Quality and Offending

\begin{tabular}{lcc}
\hline \multicolumn{1}{c}{ Parameter } & Parent-reports & Child-reports \\
\hline $\mathrm{T} 1$ associations & & $.23^{* * * *}$ \\
$\mathrm{~T} 1$ bad relationship $\leftrightarrow \mathrm{T} 1$ offending & $.31^{* * * *}$ & $.05-.07^{* * * *}$ \\
Cross-lagged effects & $.04-.06^{* * *}$ & $.06-.08^{* * * *}$ \\
$\mathrm{~T}$ bad relationship $\rightarrow \mathrm{T}+1$ offending & $.10-.13^{* * *}$ & $.07-.14^{* * * *}$ \\
$\mathrm{~T}$ offending $\rightarrow \mathrm{T}+1$ bad relationship & $.05-.10^{* * * *}$ & \\
Correlated change & \\
$\mathrm{T}$ bad relationship $\leftrightarrow \mathrm{T}$ offending &
\end{tabular}

Note. All values indicate the range of standardized effects $(\beta s)$ across childhood, early adolescence, and middle adolescence. These models also included one and 2-year stability, but these values are not displayed. Models fit statistics revealed good model fit for both models: CFI $\geq .97$; TLI $\geq .96$; RMSEA $\leq .04$. These results are graphically presented in Figure 1.

${ }^{*} p \leq .05 .{ }^{* * *} p \leq .01{ }^{* * * *} p \leq .001$.

With respect to the longitudinal cross-lagged effects between poor parent-child relationships and delinquency, clear bidirectional effects were found. Both for mothers' and for boys' responses, and across the different developmental periods, poorer parent-child relationship quality preceded higher relative levels of delinquency one year later (range of effects: $\beta=.04-.07, p<$ .001 ), and higher levels of delinquency also preceded relatively poorer parent-child relationships (range of effects: $\beta=.06-.13$, $p<.001)$.

Inspection of the 95\%-confidence intervals of the unstandardized values revealed slightly stronger $\mathrm{T} 1$ associations with parent-reported data, but no significant differences between the parent- and childreported longitudinal cross-lagged effects or correlated changes. Hence, significant and bidirectional cross-lagged effects between poor parent-child relationships and children's delinquency were found for children, early adolescents, and middle adolescents, with different informants. Figure 1 presents these significant bidirectional longitudinal associations for both informants.

\section{Overlapping Development}

The second aim of this study was to examine whether meanlevel developmental processes in offending overlapped significantly with mean-level development of parent-child relationships. Therefore, we first examined the univariate development of offending, and of parent-child relationship quality, between age 7 to 16 (see Table 3 for growth factors). Figure 2 shows an overall increase in seriousness of delinquency between age 10 and 13, followed by stabilization at this higher level between age 13 and 16. Figures 3 and 4 show the development of parent-child relationships according to boys and their primary caretakers. Between ages $7-10$, boys and parents both reported that their relationship improved. This was followed by a decreasing quality between ages 10-13, and stabilization between ages 13-16. Although there was significant change in the perception of the parent-child relationships for both parents and boys, boys' reports generally revealed more pronounced changes.

These mean-level growth factors of offending and parent-child relationships were then correlated in multivariate latent growth models, to test for the overlapping developmental changes between poor parent-child relationships and delinquency. Table 4 displays these correlations. For both reporters, and for each age group, we found significant associations between the intercepts of delinquency and intercepts of parent-child relationship quality $\left(r_{\text {parents }}=.45-.52, p<.001 ; r_{\text {children }}=.42-.48, p<.001\right)$, showing that poorer parent-child relationships at ages 7,10 , and 13 related moderately strongly to higher involvement in delinquency at ages 7,10 , and 13, respectively.

Additionally, and in line with our hypotheses, slope factors were strongly correlated in five out of six models $\left(r_{\text {parents }}=.51-.68\right.$, $\left.p<.05 ; r_{\text {children }}=.60-.79, p<.05\right)$, indicating that stronger increases in delinquency are associated with stronger deterioration of parent-child relationships. In the child-reported model for mid-

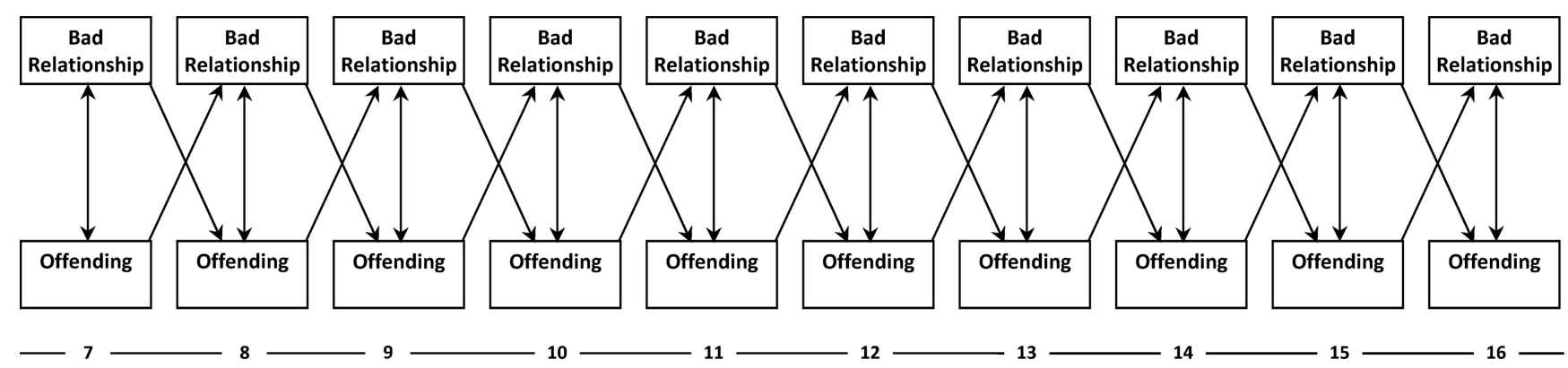

Figure 1. Significant bidirectional effects and concurrent associations in cross-lagged panel model including either parent- or child-reported bad relationship quality and offending between ages 7 and 16 . 
Table 3

Univariate Growth of Bad Relationship Quality and Delinquency in Childhood, Early Adolescence, and Middle Adolescence

\begin{tabular}{|c|c|c|c|c|c|c|}
\hline \multirow[b]{2}{*}{ Model } & \multicolumn{3}{|c|}{ Mean level } & \multicolumn{3}{|c|}{ Mean change } \\
\hline & Age 7 & Age 10 & Age 13 & Age $7-10$ & Age $10-13$ & Age $13-16$ \\
\hline Offending (multi-informant) & 0.59 & 0.67 & 0.85 & .00 & $.05^{* * *}$ & -.02 \\
\hline Bad relationship quality (child) & 18.20 & 17.39 & 19.14 & $-.27^{* *}$ & $.53^{* * * *}$ & .03 \\
\hline Bad relationship quality (parent) & 22.55 & 22.18 & 22.64 & $-.14^{*}$ & $.21^{* * * *}$ & -.09 \\
\hline
\end{tabular}

Note. Using univariate growth models we estimated the level at age 7,10 and 13 and linear change over each age period (positive slope values indicate an increase and negative values a decrease). Values represent unstandardized estimates. All mean levels (intercepts) were significant. The informant is indicated between parentheses. All models had adequate fit statistics: CFI $\geq .95$; TLI $\geq .94 ;$ RMSEA $\leq .08$. These univariate developmental changes are graphically displayed in Figures 2, 3 and 4

${ }_{*}^{*} p \leq .05 . *{ }^{* *} p \leq .01 .{ }^{* * * *} p \leq .001$.

dle adolescents, this slope-slope association was marginally significant $\left(r_{\text {children }}=.37, p=.08\right)$. Inspection of $95 \%$ confidence intervals around the unstandardized values revealed no significant differences between the slope-slope associations of the different models, indicating that these associations were invariant across childhood, early adolescence, and middle adolescence, and also invariant across reporters.

To summarize, in addition to the reciprocal influences between poorer parenting and higher relative levels of offending that were found with cross-lagged panel modeling, we also found that the developmental changes toward poorer parent-child relationships and changes toward higher levels of delinquency were significantly associated.

\section{Discussion}

Poor parent-child relationships have been a key component in theories on the etiology of delinquency for several decades (Glueck \& Glueck, 1950; Gottfredson \& Hirschi, 1990; Patterson \& Reid, 1982; Sampson \& Laub, 1993), and empirical findings give consistent support for this notion (e.g., Dishion \& McMahon, 1998; Hoeve et al., 2009; Keijsers, Branje, Van der Valk et al.,

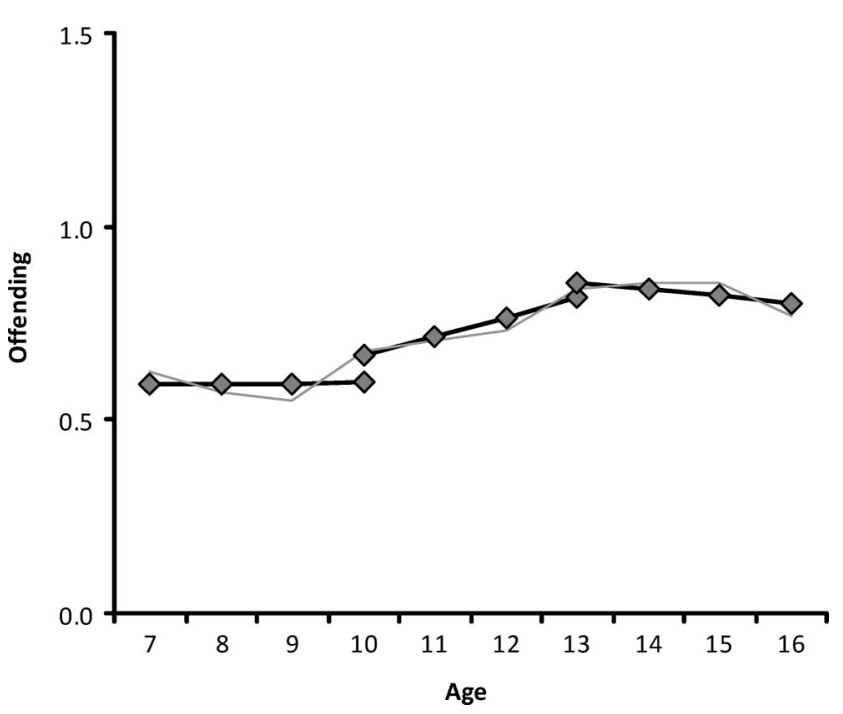

Figure 2. Development of boys' offending between ages 7 and 16 .
2010; Loeber \& Dishion, 1983; Loeber \& Stouthamer-Loeber, 1986; Patterson \& Stouthamer-Loeber, 1984). Nevertheless, it is still not clear how the association between poor parent-child relationships and delinquency unfolds over time. Coercive family process theory (Granic \& Patterson, 2006; Patterson \& Reid, 1982; Reid \& Patterson, 1989) suggests that negative day-to-day interactions are reflected in an overtime pattern, consisting of circular causality with parents and children negatively and bidirectionally affecting one another. These ongoing family dynamics then amplify the overlapping developmental changes toward increasing problem behaviors and decreasing quality of the relationship, in the long run. Hence, two types of longitudinal associations may be observed. The first type is reciprocal causality, in which poor parent-child relationships precede delinquency and delinquency precedes poorer relationships. The second type concerns overlapping mean-level developmental changes, in which changes in relationship quality and delinquency co-occur over the course of development. This longitudinal study extends the existing literature by examining both types of longitudinal associations between parent-child relationships and offending, using data covering an age-range from middle childhood (age 7) to middle adolescence (age 16).

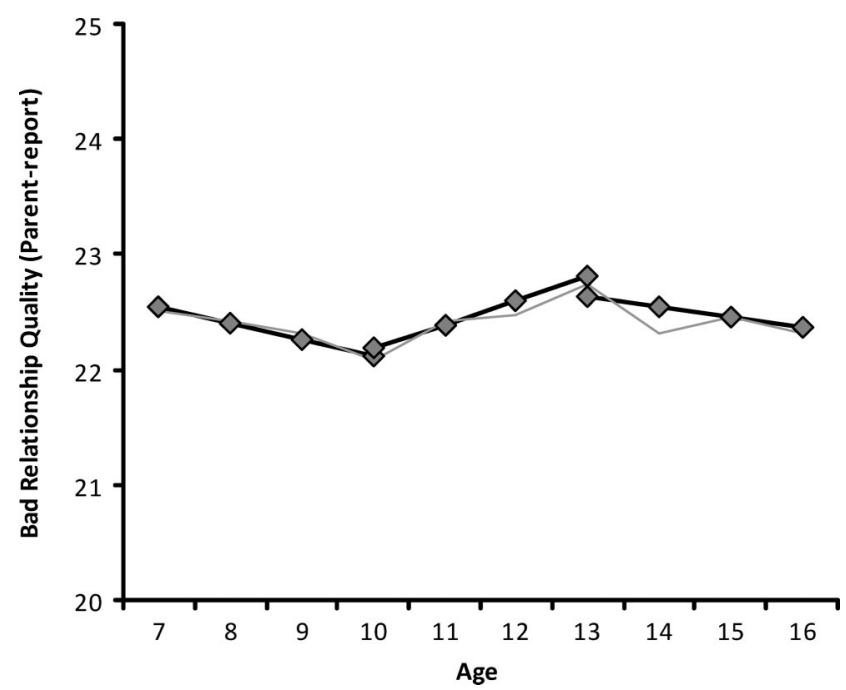

Figure 3. Development of parent-reported bad relationship quality between ages 7 and 16 . 


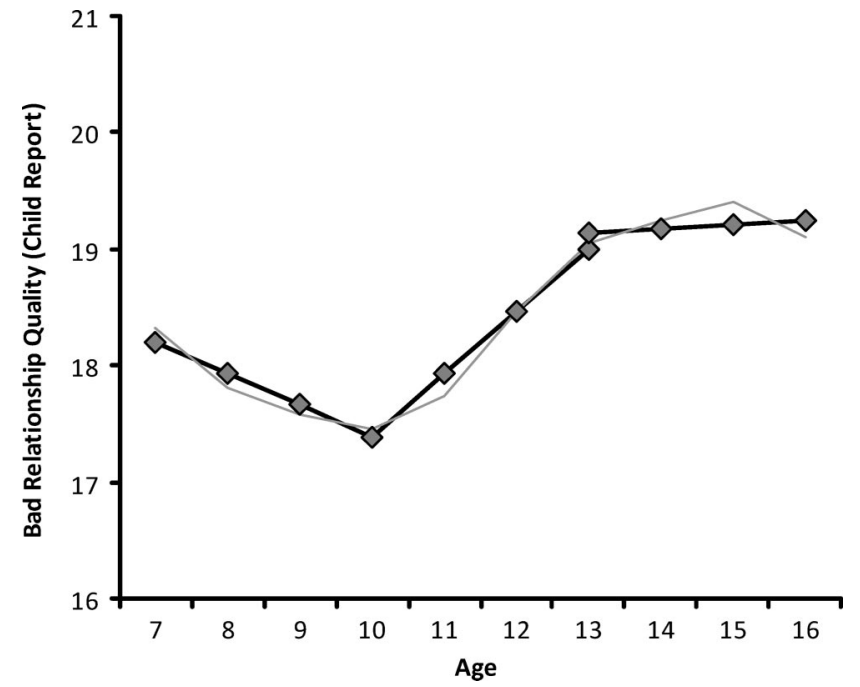

Figure 4. Development of child-reported bad relationship quality between ages 7 and 16 .

First, this study examined whether poor parent-child relationships precede a child's involvement in delinquent behaviors or whether children's bad behaviors (also) affect the quality of the parent-child relationship over time. Findings revealed bidirectional effects between parent-child relationships and delinquency, with poorer parent-child relationships preceding children's engagement in delinquency and delinquency preceding poorer parent-child relationships. These bidirectional effects were consistently found in childhood, early adolescence, and middle adolescence.

Second, this study examined developmental changes in coercive processes (Granic \& Patterson, 2006), in which it is proposed that mean-level development of parent-child relationship quality and mean-level development of delinquency go hand-in-hand. In line with the perspective that parent-child socialization occurs in the context of changing family dynamics, both mean levels of parent- child relationship quality and mean levels of delinquency changed between childhood and middle adolescence. Specifically, parentchild relationships improved in childhood and worsened in adolescence, while delinquency increased during early adolescence. Furthermore, these developmental changes in delinquency and parent-child relationships were significantly associated in five out of six models. Across age groups and informants, stronger changes toward poorer relationships were correlated with stronger increases in delinquency. These main findings and their theoretical implications will be discussed further.

\section{Reciprocal Effects Between Poor Parent-Child Relationships and Delinquency}

Coercive family process theories (Granic \& Patterson, 2006; Patterson et al., 1990) and interactional reinterpretations of children's socialization by parents (Bell, 1968; Lollis \& Kuczynski, 1997) have stressed that bidirectional influences between poorer parent-child relationships and delinquency may occur, in which poorer parenting not only precedes delinquency in time, but in which offending may also negatively affect the affective qualities of parent-child relationships. The current study builds onto these understandings by demonstrating longitudinal reciprocal effects between poorer quality parent-child relationships and delinquency in childhood, early adolescence, and middle adolescence. Notably, the strength of these bidirectional effects did not differ between the different age groups. In contrast to suggestions that parenting may more profoundly affect the misbehavior of children (e.g., Hoeve et al., 2009), our findings suggest that parent-child relationship quality and delinquency are bidirectionally and continuously related from childhood to middle adolescence.

Although parent-child relationships transform during adolescence (Collins, 1990), with children becoming more autonomous and independent from their parents (Smetana \& Asquith, 1994), the affective tie between parents and children seems to remain important. New interpretations of the literature on parental monitoring of adolescents have shown that open communication and high levels of adolescent disclosure, which are very strongly

Table 4

Standardized Associations Between Levels and Change of Bad Relationship Quality and Levels and Change of Delinquency in Childhood, Early Adolescence, and Middle Adolescence

\begin{tabular}{|c|c|c|c|c|}
\hline \multirow[b]{2}{*}{ Offending } & \multicolumn{4}{|c|}{ Bad relationship quality } \\
\hline & \multicolumn{2}{|c|}{ Child-reported } & \multicolumn{2}{|c|}{ Parent-reported } \\
\hline Childhood & Level age 7 & Change 7 to 10 & Level age 7 & Change 7 to 10 \\
\hline Level at age 7 & $.48^{* * * *}$ & $-.29^{* * *}$ & $.46^{* * * *}$ & .06 \\
\hline Change between $7-10$ & $-.42^{* *}$ & $.79^{\text {**** }}$ & -.09 & $.60^{* * *}$ \\
\hline Early adolescence & Level age 10 & Change 10 to 13 & Level age 10 & Change 10 to 13 \\
\hline Level at age 10 & $.42^{* * * *}$ & .19 & $.52^{* * * * *}$ & -.12 \\
\hline Change between $10-13$ & -.14 & $.60^{*}$ & -.04 & $.68^{* * * *}$ \\
\hline Middle adolescence & Level age 13 & Change 13 to 16 & Level age 13 & Change 13 to 16 \\
\hline Level at age 13 & $.44^{* * * * *}$ & -.09 & $.45^{* * * *}$ & -.15 \\
\hline Change between 13-16 & -.22 & .37 & -.07 & $.51^{*}$ \\
\hline
\end{tabular}

Note. All models had excellent fit statistics with $\mathrm{CFI} \geq .97$; TLI $\geq .96 ;$ RMSEA $\leq .05$.

${ }^{*} p \leq .05 .{ }^{* * *} p \leq .01 .{ }^{* * * *} p \leq .001$. 
rooted in the quality of the parent-child relationship (Keijsers, Branje, Frijns et al., 2010; Kerr et al., 1999), are essential for parents' knowledge about adolescents' daily activities, and predict lower levels of delinquency (Keijsers, Branje, Van der Valk et al., 2010; Kerr et al., 1999; Stattin \& Kerr, 2000). Moreover, in line with the bidirectional associations found in this study, open communication by adolescents affects — and is affected by —adolescent delinquency in a bidirectional fashion (Frijns, Keijsers, Branje, \& Meeus, 2010; Keijsers, Branje, Van der Valk et al., 2010). Hence, a high quality relationship, in which children feel free to disclose relevant information to parents and feel supported, may last as an important predictor and result of delinquency during adolescent years.

\section{Overlapping Developmental Changes}

Coercive family process theory (Granic \& Patterson, 2006) also stresses that parents' and children's continual reinforcement of each others' behaviors (as shown in the cross-lagged panel models) may amplify the developmental trajectories of child misbehavior, and may worsen the quality of the relationship. The bidirectional dynamics between parent-child relationships and offending may thus result in correlated development, in the direction of poorer quality relationships and higher mean levels of offending. Studies to substantiate this idea that relative influences may result in overlapping mean-level changes are currently scarce and focus only on adolescents.

Our results revealed that, on average, parent-child relationships improved between ages 7 and 10, but worsened between 10 and 13 (see also De Goede et al., 2009; Loeber et al., 2000). The mean level of delinquency increased in early adolescence, with a peak at age 13. Although this increase was expected, its timing was somewhat earlier than what is typically reported in other studies. The type of delinquency, the risk profile of the participants, and the cohort may cause high variation in this peak (Farrington, 1986; Loeber, Farrington et al., 2008; Moffitt, 1993; Steffensmeier, Allan, Harer, \& Streifel, 1989), and it is therefore not surprising that the peak occurred earlier in our sample of boys who were at relatively high risk for antisocial behavior.

In line with our hypotheses, and in addition to bidirectional linkages between offending and quality of parent-child relationships, we showed associations between mean-level changes in parent-child relationships and mean-level development of delinquency. This suggests that there is a continuous interplay between the development of parent-child relationships and offending that cannot be explained by associations at initial levels. Previous studies on adolescents had shown that stronger decreases in parental knowledge and adolescent disclosure were related to a stronger increase in the mean levels of delinquency (Keijsers et al., 2009; Laird et al., 2003). The present findings add to this existing literature by showing that these overlapping developmental changes are present in the linkage of poor parent-child relationships and delinquency from middle childhood to adolescence, as well as across informants.

\section{Limitations}

Despite a number of strengths in this study, such as the use of several informants, multiple data points, and a large sample size, there are a number of limitations that should noted. First, the findings are limited to boys' relationships with mothers, and cannot be generalized to girls and to relationships with their fathers. Fathers and mother differ in their relationships with their sons and daughters, with mother spending more time with their children and having a more intimate bond (Youniss \& Smollar, 1985). Boys' delinquency is, moreover, higher than that of girls. Given these differences, it is unclear whether the associations could generalize to other parent-child dyads. Second, the cross-lagged models yielded relatively small effect sizes. This might be due to the fact that these models not only control for temporal relative stability of each construct, but also for the T1 association and the association at each subsequent measurement occasion. In fact, it is quite common that the effects are of smaller magnitude (Raaijmakers, Engels, \& Van Hoof, 2005). Finally, this study focused on the developmental associations from middle childhood to middle adolescence, but not on the day-to-day, coercive interactions which comprise the poor relationship and that may underlie these reciprocal influences and developmental changes (Granic \& Patterson, 2006). In order to study such short-term interactions, future observational studies are needed.

\section{Conclusion}

Despite these limitations, we believe this study offers a solid first attempt to investigate how linkages between poor parentchild relationships and delinquency unfold during the development from middle childhood to middle adolescence. Consistent across childhood, early adolescence, and middle adolescence, and across parent- and child-reports, this research revealed bidirectional linkages between poor parent-child relationships and offending. It also showed that the development of parent-child relationships and the development of delinquency are associated processes from middle childhood to middle adolescence, with stronger mean-level changes toward poor relationships going hand-in-hand with stronger increases in delinquency.

\section{References}

Allison, P. D. (2003). Missing data techniques for structural equation modeling. Journal of Abnormal Psychology, 112, 545-557. doi:10.1037/ 0021-843X.112.4.545

Arim, R. G., Dahinten, S., Marshall, S. K., \& Shapka, J. D. (2011). An examination of the reciprocal relationships between adolescents' aggressive behaviors and their perceptions of parental nurturance. Journal of Youth and Adolescence, 40, 207-220. doi:10.1007/s10964-009-9493-X

Baumrind, D. (1991). The influence of parenting style on adolescent competence and substance use. Journal of Early Adolescence, 11, 5695. doi:10.1177/0272431691111004

Bell, R. Q. (1968). A reinterpretation of the direction of effects in studies of socialization. Psychological Review, 75, 81-95. doi:10.1037/ h0025583

Berndt, T. J. (1982). The features and effects of friendships in early adolescence. Child Development, 53, 1447-1460. doi:10.2307/1130071

Bosma, H. A., Jackson, S. E., Zijsling, D. H., Zani, B., Cicognani, E., Lucia Xerri, M., . . Charman, L. (1996). Who has the final say? Decisions on adolescent behaviour within the family. Journal of Adolescence, 19, 277-291. doi:10.1006/jado.1996.0025

Branje, S. J. T., Hale, W. W., III, \& Meeus, W. (2008). Reciprocal development of parent-adolescent support and adolescent problem behaviors. In M. Kerr, H. Stattin, \& R. Engels (Eds.), What can parents 
do? New insights into the role of parents in adolescent problem behavior (pp. 135-162). West Sussex, U.K.: John Wiley and Sons.

Brown, B. B. (2004). Adolescents' relationships with peers. In R. M. Lerner \& L. Steinberg (Eds.), Handbook of adolescent psychology (pp. 363-394). Hoboken, NJ: John Wiley \& Sons, Inc.

Collins, W. A. (1990). Parent-child relationships in the transition to adolescence: Continuity and change in interaction, affect, and cognition. In T. P. Gullotta, R. Montemayor, \& G. R. Adams (Eds.), From childhood to adolescence: A transitional period? (pp. 85-106). Thousand Oaks, CA: Sage.

Conger, R. D., Lorenz, F. O., \& Wickrama, K. A. S. (2004). Studying change in family relationships: The findings and their implications. In R. D. Conger, F. O. Lorenz, \& K. A. S. Wickrama (Eds.), Continuity and change in family relations: Theory, methods, and empirical findings (pp. 383-403). Mahwah, NJ: Lawrence Erlbaum.

Csikszentmihalyi, M., \& Larson, R. (1984). Being adolescent: Conflict and growth in the teenage years New York: Basic Books.

Csikszentmihalyi, M., Rathunde, K., \& Whalen, S. (1993). Talented teenagers: The roots of success and failure. Cambridge: Cambridge University Press.

Darling, N., \& Steinberg, L. (1993). Parenting style as context: An integrative model. Psychological Bulletin, 113, 487-496. doi:10.1037/00332909.113.3.487

De Goede, I., Branje, S., \& Meeus, W. (2009). Developmental changes in adolescents' perceptions of relationships with their parents. Journal of Youth and Adolescence, 38, 75-88. doi:10.1007/s10964-008-9286-7

Deković, M., Buist, K. L., \& Reitz, E. (2004). Stability and changes in problem behavior during adolescence: Latent growth analysis. Journal of Youth and Adolescence, 33, 1-12. doi:10.1023/A:1027305312204

Dishion, T. J., \& McMahon, R. J. (1998). Parental monitoring and the prevention of child and adolescent problem behavior: A conceptual and empirical formulation. Clinical Child and Family Psychology Review, 1, 61-75. doi:10.1023/A:1021800432380

Duncan, S. C., Duncan, T. E., \& Strycker, L. A. (2000). Risk and protective factors influencing adolescent problem behavior: A multivariate latent growth curve analysis. Annals of Behavioral Medicine, 22, 103-109. doi:10.1007/BF02895772

Duncan, T. E., Duncan, S. C., Strycker, L. A., Li, F., \& Alpert, A. (1999). An introduction to latent variable growth curve modeling: Concepts, issues, and applications (2nd ed.). Mahwah, NJ: Lawrence Erlbaum Associates.

Farrington, D. (1986). Age and crime. In M. Tonry \& N. Morris (Eds.), Crime and justice (pp. 29-90). Chicago, IL: University of Chicago Press.

Farrington, D. P., Loeber, R., Stouthamer-Loeber, M., Van Kammen, W. B., \& Schmidt, L. (1996). Self-reported delinquency and a combined delinquency seriousness scale based on boys, mothers, and teachers: Concurrent and predictive validity for African-Americans and Caucasians. Criminology, 34, 493-514. doi:10.1111/j.17459125.1996.tb01217.x

Fite, P. J., Colder, C. R., Lochman, J. E., \& Wells, K. C. (2006). The mutual influence of parenting and boys' externalizing behavior problems. Journal of Applied Developmental Psychology, 27, 151-263. doi:10.1016/j.appdev.2005.12.011

Frick, P. J., Christian, R. E., \& Wootton, J. M. (1999). Age trends in the association between parenting practices and conduct problems. Behavior Modification, 23, 106-128. doi:10.1177/0145445599231005

Frijns, T., Keijsers, L., Branje, S. J. T., \& Meeus, W. (2010). What parents don't know and how it may affect their children: Qualifying the disclosure-adjustment link. Journal of Adolescence, 33, 261-270. doi: 10.1016/j.adolescence.2009.05.010

Galambos, N. L., Barker, E. T., \& Almeida, D. M. (2003). Parents do matter: Trajectories of change in externalizing and internalizing prob- lems in early adolescence. Child Development, 74, 578-594. doi: 10.1111/1467-8624.7402017

Glueck, S., \& Glueck, E. (1950). Unraveling juvenile delinquency (Vol. 2). New York: Commonwealth Fund.

Gottfredson, M. R., \& Hirschi, T. (1990). A general theory of crime. Stanford, CA: Stanford University press.

Granic, I., \& Patterson, G. R. (2006). Toward a comprehensive model of antisocial development: A dynamic systems approach. Psychological Review, 113, 101-131. doi:10.1037/0033-295X.113.1.101

Hirschi, T. (1969). Causes of delinquency. Berkeley, CA: University of California Press.

Hoeve, M., Blokland, A., Dubas, J., Loeber, R., Gerris, J., \& van der Laan, P. (2008). Trajectories of delinquency and parenting styles. Journal of Abnormal Child Psychology, 36, 223-235. doi:10.1007/s10802-0079172-x

Hoeve, M., Dubas, J., Eichelsheim, V., van der Laan, P., Smeenk, W., \& Gerris, J. (2009). The relationship between parenting and delinquency: A meta-analysis. Journal of Abnormal Child Psychology, 37, 749. doi: 10.1007/s10802-009-9310-8

Jang, S. J. (1999). Age-varying effects of family, school, and peers on delinquency: A multilevel modeling test of interactional theory. Criminology, 37, 643-686. doi:10.1111/j.1745-9125.1999.tb00499.x

Keijsers, L., Branje, S., Frijns, T., Finkenauer, C., \& Meeus, W. (2010). Gender differences in keeping secrets from parents in adolescence. Developmental Psychology, 46, 293-298. doi:10.1037/a0018115

Keijsers, L., Branje, S. J. T., Van der Valk, I. E., \& Meeus, W. (2010). Reciprocal effects between parental solicitation, parental control, adolescent disclosure, and adolescent delinquency. Journal of Research on Adolescence, 20, 88-113. doi:10.1111/j.1532-7795.2009.00631.x

Keijsers, L., Frijns, T., Branje, S. J. T., \& Meeus, W. (2009). Developmental links of adolescent disclosure parental solicitation and control with delinquency: Moderation by parental support. Developmental Psychology, 45, 1314-1327. doi:10.1037/a0016693

Kerr, M., \& Stattin, H. (2000). What parents know, how they know it, and several forms of adolescent adjustment: Further support for a reinterpretation of monitoring. Developmental Psychology, 36, 366-380. doi: 10.1037/0012-1649.36.3.366

Kerr, M., Stattin, H., \& Trost, K. (1999). To know you is to trust you: Parents' trust is rooted in child disclosure of information. Journal of Adolescence, 22, 737-752. doi:10.1006/jado.1999.0266

Kline, R. B. (2005). Principles and practice of structural equation modeling (2nd ed.). New York: The Guilford Press.

Kuczynski, L., \& Parkin, C. M. (2007). Agency and bidirectionality in socialization: Interactions, transactions, and relational dialectics. In J. E. Grusec \& P. D. Hastings (Eds.), Handbook of socialization. Theory and research (pp. 259-283). New York: The Guilford Press.

Laird, R. D., Pettit, G. S., Bates, J. E., \& Dodge, K. A. (2003). Parents' monitoring-relevant knowledge and adolescents' delinquent behavior: Evidence of correlated developmental changes and reciprocal influences. Child Development, 74, 752-768. doi:10.1111/1467-8624.00566

Larson, R. W., Richards, M. H., Moneta, G., Holmbeck, G., \& Duckett, E. (1996). Changes in adolescents' daily interactions with their families from ages 10 to 18: Disengagement and transformation. Developmental Psychology, 32, 744-754. doi:10.1037/0012-1649.32.4.744

Loeber, R., \& Dishion, T. (1983). Early predictors of male delinquency: A review. Psychological Bulletin, 94, 68-99. doi:10.1037/00332909.94.1.68

Loeber, R., Drinkwater, M., Yin, Y., Anderson, S. J., Schmidt, L. C., \& Crawford, A. (2000). Stability of family interaction from ages 6 to 18 . Journal of Abnormal Child Psychology, 28, 353-369. doi:10.1023/A: 1005169026208

Loeber, R., Farrington, D. P., Stouthamer-Loeber, M., \& Raskin White, H. (2008). Violence and serious theft: Development and prediction from childhood to adulthood. Mahwah, NJ: Erlbaum. 
Loeber, R., Farrington, D. P., Stouthamer-Loeber, M., \& Van Kammen, W. B. (1998). Antisocial behavior and mental health problems: Explanatory factors in childhood and adolescence. . Mahwah, NJ: Lawrence Erlbaum Associates.

Loeber, R., Slot, N. W., \& Stouthamer-Loeber, M. (2008). A cumulative developmental model of risk and promotive factors. In R. Loeber, N. W. Slot, P. Van der laan, \& M. Hoeve (Eds.), Tomorrow's criminals (pp. 133-164). Surrey, U.K.: Ashgate Publishing Limited.

Loeber, R., \& Stouthamer-Loeber, M. (1986). Family factors as correlates and predictors of juvenile conduct problems and delinquency. Crime \& Justice, 7, 29. doi:10.1086/449112

Loeber, R., Stouthamer-Loeber, M., Farrington, D. P., Lahey, B. B., Keenan, K., \& White, H. R. (2002). Editorial introduction: Three longitudinal studies of children's development in Pittsburgh: The developmental trends study, the Pittsburgh youth study, and the Pittsburgh girls study. Criminal Behaviour and Mental Health, 12, 1-23. doi:10.1002/ cbm. 483

Lollis, S., \& Kuczynski, L. (1997). Beyond one hand clapping: Seeing bidirectionality in parent-child relations. Journal of Social and Personal Relationships, 14, 441-461. doi:10.1177/0265407597144002

Lytton, H. (1990). Child and parent effects in boys' conduct disorder: A reinterpretation. Developmental Psychology, 26, 683-697. doi:10.1037/ 0012-1649.26.5.683

Maccoby, E. E. (2007). Historical overview of socialization research and theory. In J. E. Grusec \& P. D. Hastings (Eds.), Handbook of socialization. Theory and research. New York: The Guilford Press.

Masche, J. G. (2010). Explanation of normative declines in parents' knowledge about their adolescent children. Journal of Adolescence, 33, 271284. doi:10.1016/j.adolescence.2009.08.002

Meeus, W., Branje, S., \& Overbeek, G. J. (2004). Parents and partners in crime: A six-year longitudinal study on changes in supportive relationships and delinquency in adolescence and young adulthood. Journal of Child Psychology and Psychiatry, 45, 1288-1298. doi:10.1111/j.14697610.2004.00312.x

Moffitt, T. E. (1993). Adolescence-limited and life-course-persistent antisocial behavior: A developmental taxonomy. Psychological Review, 100, 674-701. doi:10.1037/0033-295X.100.4.674

Pardini, D. A., Fite, P. J., \& Burke, J. D. (2008). Bidirectional associations between parenting practices and conduct problems in boys from childhood to adolescence: The moderating effect of age and african-american ethnicity. Journal of Abnormal Child Psychology, 36, 647-662. doi: 10.1007/s10802-007-9162-z

Patterson, G. R., Bank, L., \& Stoolmiller, M. (1990). The preadolescent's contributions to disrupted family process. In R. Montemayor, G. R. Adams, \& T. P. Gullotta (Eds.), From childhood to adolescence. A transitional period? (pp. 107-133). Newbury Park, CA: Sage.

Patterson, G. R., DeBaryshe, B. D., \& Ramsey, E. (1989). A developmental perspective on antisocial behavior. American Psychologist, 44, 329335. doi:10.1037/0003-066X.44.2.329
Patterson, G. R., \& Reid, J. B. (1982). Coercive family process: Castalia Publishing Company.

Patterson, G. R., \& Stouthamer-Loeber, M. (1984). The correlation of family management practices and delinquency. Child Development, 55, 1299-1307. doi:10.2307/1129999

Raaijmakers, Q. A. W., Engels, R. C. M. E., \& Van Hoof, A. (2005). Delinquency and moral reasoning in adolescence and young adulthood International Journal of Behavioral Development, 29, 247-258.

Reid, J. B., \& Patterson, G. R. (1989). The development of antisocial behaviour patterns in childhood and adolescence. European Journal of Personality, 3, 107-119. doi:10.1002/per.2410030205

Sampson, R. J., \& Laub, J. H. (1993). Crime in the making: Pathways and turning points through life. Cambridge, MA: Harvard University Press.

Smetana, J. G. (1988). Adolescents' and parents' conceptions of parenta authority. Child Development, 59, 321-335. doi:10.2307/1130313

Smetana, J. G., \& Asquith, P. (1994). Adolescents' and parents' conceptions of parental authority and personal autonomy. Child Development, 65, 1147-1162. doi:10.2307/1131311

Smetana, J. G., Crean, H. F., \& Daddis, C. (2002). Family processes and problem behaviors in middle-class African American adolescents. Journal of Research on Adolescence, 12, 275-304. doi:10.1111/15327795.00034

Stattin, H., \& Kerr, M. (2000). Parental monitoring: A reinterpretation. Child Development, 71, 1072-1085. doi:10.1111/1467-8624.00210

Steffensmeier, D. J., Allan, E. A., Harer, M. D., \& Streifel, C. (1989). Age and the distribution of crime. The American Journal of Sociology, 94, 803-831. doi:10.1086/229069

Stewart, E. A., Simons, R. L., Conger, R. D., \& Scaramella, L. V. (2002). Beyond the interactional relationship between delinquency and parenting practices: The contribution of legal sanctions. Journal of Research in Crime and Delinquency, 39, 36-59. doi:10.1177/002242780203900102

Stice, E., \& Barrera, M. (1995). A longitudinal examination of the reciprocal relations between perceived parenting and adolescents' substance use and externalizing behaviors. Developmental Psychology, 31, 322334. doi:10.1037/0012-1649.31.2.322

Stouthamer-Loeber, M., Loeber, R., Wei, E., Farrington, D. P., \& Wikstrom, P. O. H. (2002). Risk and promotive effects in the explanation of persistent serious delinquency in boys. Journal of Consulting and Clinical Psychology, 70, 111-123. doi:10.1037/0022-006X.70.1.111

Tremblay, R. E., \& Nagin, D. S. (2005). The developmental origins of physical aggression in humans. In R. E. Tremblay, W. H. Hartup, \& J. Archer (Eds.), Developmental origins of aggression (pp. 83-106). New York: Guilford Press.

Willoughby, T., \& Hamza, C. A. (2010). A longitudinal examination of the bidirectional associations among perceived parenting behaviors, adolescent disclosure and problem behavior across the high school years Journal of Youth and Adolescence, 1-16.

Youniss, J., \& Smollar, J. (1985). Adolescent relations with mothers, fathers, and friends. Chicago, IL: University of Chicago Press. 


\section{Appendix}

Table A1

Full Correlation Tables (Standardized Coefficients)

\begin{tabular}{|c|c|c|c|c|c|c|c|c|c|c|c|c|c|c|c|}
\hline Variables & 1 & 2 & 3 & 4 & 5 & 6 & 7 & 8 & 9 & 10 & 11 & 12 & 13 & 14 & 15 \\
\hline 1. Delinquency | age 7 & 1.000 & $.475^{* *}$ & $.371^{* * *}$ & $.325^{\text {*** }}$ & $.248^{* * *}$ & $.289^{* *}$ & $.275^{\text {*** }}$ & $.189^{* *}$ & $.191^{* *}$ & 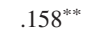 & $.310^{* * *}$ & $.271^{* * *}$ & $.292^{* * *}$ & $.270^{\text {*** }}$ & $.296^{\text {*** }}$ \\
\hline 2. Delinquency age 8 & 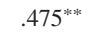 & 1.000 & $.492^{* *}$ & $.360^{\text {*2* }}$ & $.292^{* *}$ & $.326^{* * *}$ & $.308^{* * *}$ & $.249^{* * *}$ & $.221^{* * *}$ & $.178^{\text {*** }}$ & $.246^{\text {*** }}$ & $.260^{* * *}$ & $.313^{* * *}$ & 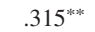 & $.320^{* * *}$ \\
\hline 3. Delinquency | age 9 & $.371^{\text {*** }}$ & $.492^{* * *}$ & 1.000 & $.456^{\text {*** }}$ & $.322^{* * *}$ & $.282^{* * *}$ & $.316^{\text {*2* }}$ & $.253^{\text {*** }}$ & $.243^{\text {*** }}$ & $.177^{\text {皮冰 }}$ & $.234^{* * *}$ & $.276^{* * *}$ & $.366^{* *}$ & $.351^{\text {*** }}$ & $.303^{\text {*** }}$ \\
\hline 4. Delinquency $\mid$ age 10 & $.325^{\text {** }}$ & $.360^{* * *}$ & $.456^{* * *}$ & 1.000 & $.361^{* * *}$ & $.427^{* *}$ & $.326^{\text {*** }}$ & $.356^{\text {** }}$ & $.241^{* * *}$ & $.216^{* * *}$ & $.213^{\text {*** }}$ & $.266^{* * *}$ & $.280^{* *}$ & $.329^{* * *}$ & $.309^{* * *}$ \\
\hline 5. Delinquency | age 11 & $.248^{* * *}$ & $.292^{* *}$ & $.322^{* * *}$ & $.361^{* * *}$ & 1.000 & $.537^{* *}$ & $.490^{\text {*** }}$ & $.454^{* *}$ & $.439^{* * *}$ & $.315^{* *}$ & $.153^{* * *}$ & $.155^{* *}$ & $.195^{* *}$ & $.192^{\text {*** }}$ & $.291^{* * *}$ \\
\hline 6. Delinquency | age 12 & $.289^{* * *}$ & $.326^{* * *}$ & $.282^{\text {*** }}$ & $.427^{* * *}$ & $.537^{* * *}$ & 1.000 & $.506^{* * *}$ & $.473^{\text {*** }}$ & $.383^{* * *}$ & $.263^{* * *}$ & $.252^{\text {*** }}$ & $.231^{* * *}$ & $.248^{* *}$ & $.224^{* * *}$ & $.220^{* * *}$ \\
\hline 7. Delinquency | age 13 & $.275^{\text {** }}$ & $.308^{* * *}$ & $.316^{* * *}$ & $.326^{* * *}$ & $.490^{* *}$ & $.506^{* *}$ & 1.000 & $.503^{* *}$ & $.509^{* * *}$ & $.325^{\text {** }}$ & $.224^{\text {*** }}$ & $.261^{\text {*** }}$ & $.291^{* * *}$ & $.259^{\text {*** }}$ & $.299^{* * *}$ \\
\hline 8. Delinquency | age 14 & $.189^{\text {*** }}$ & $.249^{* * *}$ & $.253^{* * *}$ & $.356^{* * *}$ & $.454^{* *}$ & $.473^{* * *}$ & $.503^{* * *}$ & 1.000 & $.475^{* * *}$ & $.482^{\text {*** }}$ & $.202^{* * *}$ & $.223^{* * *}$ & $.215^{* * *}$ & $.267^{\text {*** }}$ & $.254^{* * *}$ \\
\hline 9. Delinquency $\mid$ age 15 & $.191^{* * *}$ & $.221^{\text {** }}$ & $.243^{* * *}$ & $.241^{* * *}$ & $.439^{* * *}$ & $.383^{* * *}$ & $.509^{\text {*** }}$ & $.475^{\text {*** }}$ & 1.000 & $.453^{\text {*** }}$ & $.205^{\text {*** }}$ & $.187^{* * * *}$ & $.227^{* * *}$ & $.230^{\text {*** }}$ & $.240^{\text {*** }}$ \\
\hline 10. Delinquency $\mid$ age 16 & $.158^{* * *}$ & $.178^{\text {*** }}$ & $.177^{* * *}$ & $.216^{* * *}$ & $.315^{\text {** }}$ & $.263^{* * *}$ & $.325^{\text {*** }}$ & $.482^{* * *}$ & $.453^{* *}$ & 1.000 & $.200^{* * * *}$ & $.220^{* * * *}$ & $.249^{* * *}$ & $.282^{\text {*** }}$ & $.295^{\text {*** }}$ \\
\hline $\begin{array}{l}\text { 11. Bad relationship } \\
\text { parent-report | age } 7\end{array}$ & $.310^{* * *}$ & $.246^{* *}$ & $.234^{* * *}$ & 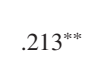 & $.153^{* * *}$ & $.252^{* * *}$ & $.224^{* * *}$ & $.202^{* *}$ & $.205^{* * *}$ & $.200^{* * *}$ & 1.000 & $.745^{* * *}$ & $.722^{* * *}$ & $.687^{* * *}$ & $.612^{\text {*** }}$ \\
\hline $\begin{array}{l}\text { 12. Bad relationship } \\
\text { parent-report | age } 8\end{array}$ & $.271^{* * *}$ & $.260^{* * *}$ & $.276^{* * *}$ & $.266^{* * *}$ & $.155^{* *}$ & $.231^{* * *}$ & $.261^{\text {*** }}$ & $.223^{* * *}$ & $.187^{* * *}$ & $.220^{\text {*** }}$ & $.745^{\text {*** }}$ & 1.000 & $.786^{* * *}$ & $.748^{\text {*** }}$ & $.656^{\text {*** }}$ \\
\hline $\begin{array}{l}\text { 13. Bad relationship } \\
\text { parent-report | age } 9\end{array}$ & $.292^{* * *}$ & $.313^{\text {*** }}$ & $.366^{* * *}$ & $.280^{\text {*** }}$ & $.195^{\text {** }}$ & $.248^{* * *}$ & $.291^{\text {*ak }}$ & $.215^{\text {*** }}$ & $.227^{\text {*** }}$ & $.249^{\text {*** }}$ & $.722^{\text {*** }}$ & $.786^{* * *}$ & 1.000 & $.819^{\text {*** }}$ & $.733^{\text {*** }}$ \\
\hline $\begin{array}{l}\text { 14. Bad relationship } \\
\text { parent-report | age } 10\end{array}$ & $.270^{\text {*** }}$ & $.315^{\text {*** }}$ & $.351^{* * *}$ & $.329^{* * *}$ & $.192^{* * *}$ & $.224^{* * *}$ & $.259^{\text {*** }}$ & $.267^{* * *}$ & $.230^{* * *}$ & $.282^{\text {*** }}$ & $.687^{\text {*** }}$ & $.748^{* * *}$ & $.819^{\text {*** }}$ & 1.000 & $.758^{* * *}$ \\
\hline $\begin{array}{l}\text { 15. Bad relationship } \\
\text { parent-report | age } 11\end{array}$ & $.296^{* * *}$ & $.320^{* * *}$ & $.303^{* * *}$ & $.309^{* * *}$ & $.291^{* * *}$ & $.220^{* * *}$ & $.299^{\text {*** }}$ & $.254^{* * *}$ & $.240^{* * *}$ & $.295^{\text {*** }}$ & $.612^{* * *}$ & $.656^{* * *}$ & $.733^{* * *}$ & $.758^{\text {*** }}$ & 1.000 \\
\hline $\begin{array}{l}\text { 16. Bad relationship } \\
\text { parent-report | age } 12\end{array}$ & $.252^{* * *}$ & $.274^{* * *}$ & $.275^{\text {*** }}$ & $.247^{* * \cdot k}$ & $.227^{\text {*** }}$ & $.226^{* * *}$ & $.311^{\text {*** }}$ & $.260^{\text {*** }}$ & $.237^{* * *}$ & $.265^{\text {*** }}$ & $.569^{* * *}$ & $.639^{* * *}$ & $.709^{* * *}$ & $.704^{\text {*** }}$ & $.779^{\text {*** }}$ \\
\hline $\begin{array}{l}\text { 17. Bad relationship } \\
\text { parent-report | age } 13\end{array}$ & $.206^{* * *}$ & $.336^{* *}$ & $.234^{* * *}$ & $.228^{* * *}$ & $.239^{* * *}$ & $.212^{* * *}$ & $.314^{* * * *}$ & $.301^{* * *}$ & $.210^{* * *}$ & $.254^{* * *}$ & $.488^{* * *}$ & $.553^{* * *}$ & $.561^{* * *}$ & $.601^{* * *}$ & $.710^{\text {*** }}$ \\
\hline $\begin{array}{l}\text { 18. Bad relationship } \\
\text { parent-report | age } 14\end{array}$ & $.227^{* * *}$ & $.222^{* *}$ & $.275^{* * *}$ & $.235^{* * *}$ & $.217^{* * *}$ & $.178^{* * *}$ & $.257^{* * *}$ & $.330^{\text {*** }}$ & $.255^{* * *}$ & $.281^{* * *}$ & $.524^{* * *}$ & $.561^{* * *}$ & $.589^{* * *}$ & $.628^{* * *}$ & $.638^{* * *}$ \\
\hline $\begin{array}{l}\text { 19. Bad relationship } \\
\text { parent-report | age } 15\end{array}$ & $.181^{* * *}$ & $.209^{* * *}$ & $.215^{* * *}$ & $.188^{* * *}$ & $.179^{* *}$ & $.120^{*}$ & $.224^{\text {*** }}$ & $.322^{* * *}$ & $.269^{* * *}$ & $.293^{* * *}$ & $.466^{* * *}$ & $.502^{* * *}$ & $.525^{\text {*** }}$ & $.598^{\text {*** }}$ & $.594^{* * *}$ \\
\hline $\begin{array}{l}\text { 20. Bad relationship } \\
\text { parent-report | age } 16\end{array}$ & $.194^{* * *}$ & $.259^{\text {*** }}$ & $.248^{* * *}$ & $.200^{* * *}$ & $.169^{* * *}$ & $.196^{* * *}$ & $.249^{\text {*** }}$ & $.316^{\text {*** }}$ & $.262^{* *}$ & $.338^{\text {*** }}$ & $.493^{\text {*** }}$ & $.511^{* * *}$ & $.562^{* * *}$ & $.579^{\text {*** }}$ & $.593^{\text {*** }}$ \\
\hline $\begin{array}{l}\text { 21. Bad relationship } \\
\text { child-report | age } 7\end{array}$ & $.226^{* * *}$ & $.154^{* * *}$ & .063 & .053 & .090 & .064 & $.095^{*}$ & .043 & .061 & $.126^{\text {*** }}$ & $.122^{\text {*** }}$ & $.106^{*}$ & $.110^{*}$ & .056 & .085 \\
\hline $\begin{array}{l}\text { 22. Bad relationship } \\
\text { child-report } \mid \text { age } 8\end{array}$ & $.227^{* * *}$ & $.235^{\text {*** }}$ & $.128^{* * *}$ & $.141^{* * *}$ & .087 & .071 & .084 & $.116^{*}$ & .050 & .088 & $.173^{\text {*** }}$ & $.182^{* * *}$ & $.184^{* * * *}$ & $.173^{\text {*** }}$ & $.181^{\text {*** }}$ \\
\hline $\begin{array}{l}\text { 23. Bad relationship } \\
\text { child-report | age } 9\end{array}$ & $.174^{\text {*** }}$ & $.208^{\text {*** }}$ & $.217^{* * *}$ & $.217^{\text {*** }}$ & $.210^{* * *}$ & $.124^{* * *}$ & $.130^{* * *}$ & .069 & .075 & $.125^{\text {*** }}$ & $.152^{\text {*** }}$ & $.168^{* * *}$ & $.171^{* * *}$ & $.182^{\text {*** }}$ & $.194^{* * *}$ \\
\hline $\begin{array}{l}\text { 24. Bad relationship } \\
\text { child-report | age } 10\end{array}$ & .085 & $.163^{\text {*** }}$ & $.130^{* * * *}$ & $.206^{* * *}$ & $.167^{* * *}$ & $.145^{* * *}$ & $.135^{* * *}$ & $.139^{* * *}$ & .059 & .082 & .076 & $.116^{*}$ & $.104^{*}$ & $.137^{\text {*** }}$ & $.145^{\text {*** }}$ \\
\hline $\begin{array}{l}\text { 25. Bad relationship } \\
\text { child-report | age } 11\end{array}$ & $.095^{*}$ & $.180^{\text {*** }}$ & $.182^{* * *}$ & $.226^{* * *}$ & $.271^{* * *}$ & $.190^{* * *}$ & $.201^{* * *}$ & $.135^{\text {*** }}$ & $.164^{* * *}$ & 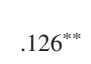 & .022 & $.092^{*}$ & $.108^{*}$ & $.108^{*}$ & $.194^{* * *}$ \\
\hline $\begin{array}{l}\text { 26. Bad relationship } \\
\text { child-report | age } 12\end{array}$ & $.113^{*}$ & $.174^{* * *}$ & $.154^{* * *}$ & $.165^{\text {*** }}$ & $.286^{* *}$ & $.291^{* * *}$ & $.269^{* * *}$ & $.199^{* * *}$ & $.182^{* * *}$ & .076 & $.113^{*}$ & .078 & $.113^{*}$ & $.114^{*}$ & $.157^{* * *}$ \\
\hline $\begin{array}{l}\text { 27. Bad relationship } \\
\text { child-report | age } 13\end{array}$ & .083 & $.152^{\text {*** }}$ & $.199^{* * *}$ & $.227^{\text {*** }}$ & $.310^{\text {*** }}$ & $.265^{\text {*** }}$ & $.255^{\text {*** }}$ & $.249^{\text {*** }}$ & $.184^{* * *}$ & $.237^{\text {皮决 }}$ & .060 & $.168^{* * *}$ & $.161^{* * *}$ & $.139^{\text {*** }}$ & $.175^{* * *}$ \\
\hline $\begin{array}{l}\text { 28. Bad relationship } \\
\text { child-report | age } 14\end{array}$ & .057 & $.196^{* * *}$ & $.235^{* * *}$ & $.132^{\text {*** }}$ & $.255^{\text {*** }}$ & $.276^{* * *}$ & $.248^{\text {*** }}$ & $.255^{\text {*** }}$ & $.261^{* * *}$ & $.154^{* * *}$ & $.107^{*}$ & $.097^{*}$ & $.116^{*}$ & $.105^{*}$ & $.114^{*}$ \\
\hline $\begin{array}{l}\text { 29. Bad relationship } \\
\text { child-report } \mid \text { age } 15\end{array}$ & .042 & $.148^{* * *}$ & $.173^{* * *}$ & $.160^{* * *}$ & $.249^{* * *}$ & $.221^{* * *}$ & $.280^{* * *}$ & $.258^{\text {*** }}$ & $.343^{* * *}$ & $.245^{* * *}$ & $.185^{\text {*** }}$ & $.225^{* * *}$ & $.252^{* * *}$ & $229^{\text {*** }}$ & $.206^{* * *}$ \\
\hline $\begin{array}{l}\text { 30. Bad relationship } \\
\text { child-report | age } 16\end{array}$ & .052 & $.186^{* * *}$ & $.184^{* * *}$ & $.184^{* * *}$ & .068 & $.108^{*}$ & $.165^{\text {*** }}$ & $.142^{\text {*** }}$ & $.183^{* * *}$ & $.231^{* * *}$ & $.156^{\text {** }}$ & $.183^{* * *}$ & $.222^{\text {*** }}$ & $.233^{\text {*** }}$ & $.203^{\text {** }}$ \\
\hline
\end{tabular}

${ }^{*} p \leq .05 . \quad{ }^{* * *} p \leq .01 . \quad{ }^{* * * *} p \leq .001$. 


\begin{tabular}{|c|c|c|c|c|c|c|c|c|c|c|c|c|c|c|}
\hline 16 & 17 & 18 & 19 & 20 & 21 & 22 & 23 & 24 & 25 & 26 & 27 & 28 & 29 & 30 \\
\hline $.252^{\text {*** }}$ & $.206^{\text {*** }}$ & $.227^{* * *}$ & $.181^{\text {*** }}$ & $.194^{* * *}$ & $.226^{\text {*** }}$ & $.227^{\text {*** }}$ & $.174^{\text {*** }}$ & .085 & $.095^{*}$ & $.113^{*}$ & .083 & .057 & .042 & .052 \\
\hline $.274^{* * *}$ & $.336^{\text {*** }}$ & $.222^{* * *}$ & $.209^{* * *}$ & $.259^{* * *}$ & $.154^{* * *}$ & $.235^{\text {*** }}$ & $.208^{* * *}$ & $.163^{\text {** }}$ & $.180^{\text {*** }}$ & $.174^{* * *}$ & $.152^{\text {*** }}$ & $.196^{\text {** }}$ & $.148^{\text {*** }}$ & $.186^{\text {** }}$ \\
\hline $.275^{* * *}$ & $.234^{* * *}$ & $.275^{\text {*** }}$ & $.215^{\text {** }}$ & $.248^{* * *}$ & .063 & $.128^{\text {*** }}$ & $.217^{\text {*** }}$ & $.130^{* * *}$ & $.182^{\text {*** }}$ & 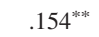 & $.199^{\text {*** }}$ & $.235^{\text {*** }}$ & $.173^{\text {*** }}$ & $.184^{\text {** }}$ \\
\hline $.247^{\text {*** }}$ & $.228^{* * *}$ & $.235^{\text {*** }}$ & $.188^{* * *}$ & $.200^{\text {*** }}$ & .053 & $.141^{\text {** }}$ & $.217^{\text {*** }}$ & $.206^{* * *}$ & $.226^{* * *}$ & $.165^{\text {*** }}$ & $.227^{\text {*** }}$ & $.132^{\text {*** }}$ & $.160^{\text {*** }}$ & $.184^{\text {*** }}$ \\
\hline $227^{\text {*** }}$ & $.239^{* * *}$ & $.217^{\text {*** }}$ & $.179^{\text {*** }}$ & $.169^{\text {** }}$ & .090 & .087 & $.210^{\text {*** }}$ & $.167^{\text {*** }}$ & $.271^{\text {*** }}$ & $.286^{* * *}$ & $.310^{\text {*** }}$ & $.255^{\text {*** }}$ & $.249^{\text {*** }}$ & .068 \\
\hline $.226^{\text {** }}$ & $.212^{\text {*** }}$ & $.178^{\text {*** }}$ & $.120^{*}$ & $.196^{\text {** }}$ & .064 & .071 & $.124^{\text {*** }}$ & $.145^{\text {** }}$ & $.190^{\text {*** }}$ & $.291^{\text {*** }}$ & $.265^{\text {** }}$ & $.276^{\text {*** }}$ & $.221^{\text {*** }}$ & $.108^{*}$ \\
\hline $.311^{* * *}$ & $.314^{* * *}$ & $.257^{\text {*** }}$ & $.224^{\text {*** }}$ & $.249^{\text {*** }}$ & $.095^{*}$ & .084 & $.130^{\text {*** }}$ & $.135^{\text {** }}$ & $.201^{* * *}$ & $.269^{\text {*** }}$ & $.255^{\text {*** }}$ & $.248^{\text {*** }}$ & $.280^{\text {*** }}$ & $.165^{\text {** }}$ \\
\hline $.260^{* * *}$ & $.301^{\text {*** }}$ & $.330^{* * *}$ & $.322^{\text {*** }}$ & $.316^{* * *}$ & .043 & $.116^{*}$ & .069 & $.139^{* * *}$ & $.135^{\text {*** }}$ & $.199^{* * *}$ & $.249^{\text {*** }}$ & $.255^{\text {** }}$ & $.258^{* * *}$ & $.142^{* * *}$ \\
\hline $.237^{\text {**k }}$ & $.210^{\text {*** }}$ & $.255^{\text {*** }}$ & $.269^{\text {*** }}$ & $.262^{\text {*** }}$ & .061 & .050 & .075 & .059 & $.164^{* * *}$ & $.182^{\text {*** }}$ & $.184^{\text {*** }}$ & $.261^{\text {*** }}$ & $.343^{\text {*** }}$ & $.183^{\text {*** }}$ \\
\hline $.265^{* * *}$ & $.254^{* * *}$ & $.281^{* * * *}$ & $.293^{\text {*** }}$ & $.338^{* * *}$ & $.126^{* * *}$ & .088 & $.125^{\text {*** }}$ & .082 & $.126^{\text {*** }}$ & .076 & $.237^{\text {*** }}$ & $.154^{\text {*** }}$ & $.245^{\text {*** }}$ & $.231^{\text {*** }}$ \\
\hline $.569^{* * *}$ & $.488^{* * *}$ & $.524^{* * *}$ & $.466^{* * *}$ & $.493^{\text {*** }}$ & $.122^{\text {*** }}$ & $.173^{\text {*** }}$ & $.152^{\text {*** }}$ & .076 & .022 & $.113^{*}$ & .060 & $.107^{*}$ & $.185^{\text {*** }}$ & $.156^{* * *}$ \\
\hline $.639^{\text {*** }}$ & $.553^{* * *}$ & $.561^{* * *}$ & $.502^{\text {*** }}$ & $.511^{\text {*** }}$ & $.106^{*}$ & $.182^{\text {*** }}$ & $.168^{\text {*** }}$ & $.116^{*}$ & $.092^{*}$ & .078 & $.168^{\text {*** }}$ & $.097^{*}$ & $.225^{\text {*** }}$ & $.183^{\text {*** }}$ \\
\hline $.709^{\text {*** }}$ & $.561^{\text {*** }}$ & $.589^{* * *}$ & $.525^{\text {*** }}$ & $.562^{* * *}$ & $.110^{*}$ & $.184^{* * *}$ & $.171^{* * *}$ & $.104^{*}$ & $.108^{*}$ & $.113^{*}$ & $.161^{\text {*** }}$ & $.116^{*}$ & $.252^{\text {*** }}$ & $.222^{\text {*** }}$ \\
\hline $.704^{* * *}$ & $.601^{\text {*** }}$ & $.628^{* * *}$ & $.598^{\text {*** }}$ & $.579^{* * *}$ & .056 & $.173^{\text {*** }}$ & $.182^{\text {*** }}$ & $.137^{\text {*** }}$ & $.108^{*}$ & $.114^{*}$ & $.139^{\text {*** }}$ & $.105^{*}$ & $.229^{\text {*** }}$ & $.233^{* * *}$ \\
\hline $.779^{* * *}$ & $.710^{\text {*** }}$ & $.638^{\text {*** }}$ & $.594^{\text {*** }}$ & $.593^{* * *}$ & .085 & $.181^{\text {*** }}$ & $.194^{\text {*** }}$ & $.145^{\text {** }}$ & $.194^{* * *}$ & $.157^{* * *}$ & $.175^{\text {*** }}$ & $.114^{*}$ & $.206^{\text {*** }}$ & $.203^{* *}$ \\
\hline 1.000 & $.687^{\text {*** }}$ & $.664^{* * *}$ & $.638^{* * *}$ & $.619^{\text {*** }}$ & .090 & $.170^{\text {*** }}$ & $.154^{\text {*** }}$ & $.126^{\text {*** }}$ & $.154^{\text {*** }}$ & $.174^{* * *}$ & $.178^{\text {*** }}$ & $.135^{\text {** }}$ & $.189^{\text {*** }}$ & $.178^{* * *}$ \\
\hline $.687^{\text {**k }}$ & 1.000 & $.720^{* * *}$ & $.635^{\text {*** }}$ & $.626^{\text {*** }}$ & .048 & $.155^{\text {** }}$ & $.152^{* * *}$ & $.144^{* * *}$ & $.147^{\text {*** }}$ & $.135^{* * *}$ & $.196^{\text {*** }}$ & $.177^{* * *}$ & $.174^{* * *}$ & $.233^{* * *}$ \\
\hline $.664^{* * *}$ & $.720^{* * *}$ & 1.000 & $.728^{\text {*** }}$ & $.654^{* * *}$ & .062 & $.136^{* * *}$ & $.138^{\text {*** }}$ & $.097^{*}$ & $.138^{\text {*** }}$ & $.161^{* * *}$ & $.155^{\text {*** }}$ & $.200^{* * *}$ & $.186^{\text {*** }}$ & $.194^{\text {*2* }}$ \\
\hline $.638^{\text {*** }}$ & $.635^{\text {*** }}$ & $.728^{* * *}$ & 1.000 & $.714^{\text {*** }}$ & .054 & $.148^{* *}$ & $.138^{* * *}$ & .070 & .088 & $.168^{* * *}$ & $.216^{\text {*** }}$ & $.206^{* * *}$ & $.281^{\text {*** }}$ & $.269^{\text {*** }}$ \\
\hline $.619^{\text {*** }}$ & $.626^{* *}$ & $.654^{* * *}$ & $.714^{\text {*** }}$ & 1.000 & .009 & $.120^{*}$ & .064 & .044 & .064 & $.160^{\text {*** }}$ & $.215^{\text {*** }}$ & $.205^{\text {*** }}$ & $.265^{\text {*** }}$ & $.339^{\text {** }}$ \\
\hline .090 & .048 & .062 & .054 & .009 & 1.000 & $.463^{\text {** }}$ & $.396^{\text {*** }}$ & $.318^{\text {*** }}$ & $.213^{\text {*** }}$ & $.179^{\text {*** }}$ & $.194^{\text {*** }}$ & $.211^{\text {*** }}$ & $.102^{*}$ & .072 \\
\hline $.170^{\text {*** }}$ & $.155^{\text {*** }}$ & $.136^{* * *}$ & $.148^{\text {*** }}$ & $.120^{*}$ & $.463^{* * *}$ & 1.000 & $.583^{\text {*** }}$ & $.492^{\text {*** }}$ & $.315^{\text {*** }}$ & $.311^{\text {*** }}$ & $.239^{\text {*** }}$ & $.228^{* * *}$ & $.144^{\text {*** }}$ & $.118^{*}$ \\
\hline $.154^{* * *}$ & $.152^{* * *}$ & $.138^{\text {*** }}$ & $.138^{\text {*** }}$ & .064 & $.396^{* * *}$ & $.583^{\text {** }}$ & 1.000 & $.598^{\text {*** }}$ & $.481^{* * *}$ & $.417^{\text {*** }}$ & $.386^{\text {*** }}$ & $.363^{\text {*** }}$ & $.245^{* * *}$ & $.195^{\text {** }}$ \\
\hline $.126^{* * *}$ & $.144^{* * *}$ & $.097^{*}$ & .070 & .044 & $.318^{* * *}$ & $.492^{* * *}$ & $.598^{* * *}$ & 1.000 & $.558^{\text {*** }}$ & $.499^{* * *}$ & $.393^{* * *}$ & $.376^{\text {*** }}$ & $.274^{* * *}$ & $.230^{* * *}$ \\
\hline $.154^{* * *}$ & $.147^{* * *}$ & $.138^{* * *}$ & .088 & .064 & $.213^{* *}$ & $.315^{\text {** }}$ & $.481^{* * *}$ & $.558^{\text {*** }}$ & 1.000 & $.610^{* * *}$ & $.479^{* * *}$ & $.441^{\text {*** }}$ & $.395^{\text {*** }}$ & $.268^{* *}$ \\
\hline $.174^{* * *}$ & $.135^{* *}$ & $.161^{* * *}$ & $.168^{\text {*** }}$ & $.160^{* * *}$ & $.179^{\text {*** }}$ & $.311^{\text {*** }}$ & 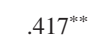 & $.499^{* * *}$ & $.610^{\text {*** }}$ & 1.000 & $.561^{\text {*** }}$ & $.567^{\text {*** }}$ & $.456^{\text {*** }}$ & $.369^{\text {*** }}$ \\
\hline $.178^{\text {*** }}$ & $.196^{* * *}$ & $.155^{\text {*** }}$ & $.216^{* * *}$ & $.215^{\text {*** }}$ & $.194^{* * *}$ & $.239^{* * *}$ & $.386^{* * *}$ & $.393^{* * *}$ & $.479^{\text {*** }}$ & $.561^{* * *}$ & 1.000 & $.598^{* * *}$ & $.523^{\text {*** }}$ & $.428^{* * *}$ \\
\hline $.135^{\text {*** }}$ & $.177^{* * *}$ & $.200^{* * *}$ & $.206^{* * *}$ & $.205^{* * *}$ & $.211^{* * *}$ & $.228^{* * *}$ & $.363^{\text {** }}$ & $.376^{\text {*** }}$ & $.441^{* * *}$ & $.567^{* * *}$ & $.598^{\text {*** }}$ & 1.000 & $.592^{* * *}$ & $.516^{\text {** }}$ \\
\hline $.189^{* * *}$ & $.174^{* * *}$ & $.186^{* * *}$ & $.281^{\text {*** }}$ & $.265^{* * *}$ & $.102^{*}$ & $.144^{\text {*** }}$ & $.245^{\text {*** }}$ & $.274^{\text {*** }}$ & $.395^{\text {*** }}$ & $.456^{\text {*** }}$ & $.523^{\text {*** }}$ & $.592^{\text {*** }}$ & 1.000 & $.526^{* * *}$ \\
\hline $.178^{* * *}$ & $.233^{* * *}$ & $.194^{* * *}$ & $.269^{\text {*** }}$ & $.339^{* *}$ & .072 & $.118^{*}$ & $.195^{\text {*** }}$ & $.230^{* *}$ & $.268^{* * *}$ & $.369^{* * *}$ & $.428^{\text {*** }}$ & $.516^{\text {** }}$ & $.526^{* * *}$ & 1.000 \\
\hline
\end{tabular}

Received February 16, 2009

Revision received April 18, 2011

Accepted April 20, 2011 